\title{
Percutaneous coronary intervention in acute myocardial infarction before and during the COVID-19 pandemic: first insights from a dedicated COVID-19 hospital
}

\author{
OIrzal Hadžibegović*, \\ (D)Ante Lisičić, \\ -Mario Udovičić, \\ - Miroslav Raguž, \\ Ollko Vuksanović, \\ (DOgnjen Čančarević, \\ C. Vanja Hulak-Karlak, \\ - Olvana Jurin, \\ CAleksandar Blivajs, \\ (D) Petra Vitlov, \\ (1)Boris Starčević
}

University Hospital Dubrava,

Zagreb, Croatia
KEYWORDS: myocardial infarction, percutaneous coronary intervention, COVID-19.
CITATION: Cardiol Croat. 2021:16(1-2):7. | https://doi.org/10.15836/ccar2021.7

*ADDRESS FOR CORRESPONDENCE: Irzal Hadžibegović, Klinička bolnica Dubrava, Avenija Gojka Šuška 6, HR-10000 Zagreb, Croatia. / Phone: +385-91-5333091 / E-mail: irzalh@gmail.com

ORCID: Irzal Hadžibegović, https://orcid.org/0000-0002-3768-9134 • Ante Lisičić, https://orcid.org/0000-0002-4365-9652 Mario Udovičić, https://orcid.org/0000-0001-9912-2179 • Miroslav Raguž, https://orcid.org/0000-0003-1567-8503 Ilko Vuksanović, https://orcid.org/0000-0002-4462-8647 • Ognjen Čančarević, https://orcid.org/0000-0002-1285-8042 Vanja Hulak-Karlak, https://orcid.org/0000-0003-0614-215X • Ivana Jurin, https://orcid.org/0000-0002-2637-9691 Aleksandar Blivajs, https://orcid.org/0000-0003-3404-3837 • Petra Vitlov, https://orcid.org/0000-0001-6983-1409 Boris Starčević, https://orcid.org/0000-0002-3090-2772

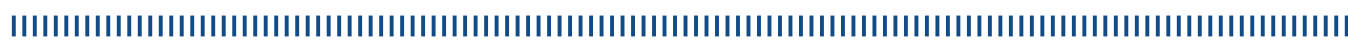

Background: COVID-19 pandemic has caused a worldwide situation of "missing patients" with acute myocardial infarction (AMI) suitable for a timely percutaneous coronary intervention (PCI). ${ }^{1}$ We aimed to investigate the impact of COVID-19 pandemic on PCI in AMI (ST elevation + non ST elevation MIs) in a hospital included in the national primary PCI network and dedicated for COVID-19 patients from Mar 2020

Patients and Methods: We compared numbers, characteristics and outcomes of patients presenting with AMI and receiving timely percutaneous intervention in our hospital between two periods: Jan 2019 - Jan 2020 ("pre-COVID-19" era) and Mar 2020 - Dec 2020 ("COVID-19" era - 9 months period with mixed hospital organization: 4 months dedicated COVID-19 only hospital, and 5 months both nonCOVID-19 and COVID-19 hospital).

Results: In the pre-COVID-19 era we performed 434 PCIs in 505 patients with AMI who received urgent/ early coronary angiography after admission (average monthly number of AMI suitable for revascularization: 42 patients), with in-hospital mortality of 3.7\%. During the COVID-19 era there were 137 PCIs in 186 patients with AMI and urgent/early coronary angiography (average monthly number of AMI suitable for revascularization: 18 patients), with in-hospital mortality of 8\%. During the COVID-19 era, there were 14 COVID-19 positive patients with acute AMI who underwent urgent angiography (8 received PCI and 6 were treated conservatively) and had in-hospital mortality of $28 \%$.

Conclusion: We found an astonishing $40 \%$ reduction in monthly rates of patients with AMI suitable for revascularization presenting to our hospital during the COVID-19 pandemic. AMI patients that were treated with PCI during the pandemic era had significantly higher mortality, mostly influenced by a very high mortality rate of COVID-19 positive patients presenting with AMI. Comprehensive analysis of national primary PCI network organization and patient awareness of AMI during COVID-19 pandemic in Croatia is warranted.

LITERATURE IIIIIIIIIIIIIIIIIIIIIIIIIIIIIIIIIIIIIIIIIIIIIIIIIIIIIIIIIIIIIIIIIIIIIIIIIIIIIIIIIIIIIIIIIIIIIIIIIIIII 1. Ruparelia N, Panoulas V. The missing acute coronary syndromes in the CoVID-19 era. Ther Adv Cardiovasc Dis. 2020 Jan-Dec;14:1753944720977732. https://doi.org/10.1177/1753944720977732 